\title{
Gastrointestinal Symptoms in Parkinson Disease: Clinical Aspects and Management
}

\author{
D. Salat-Foix, C.N. Andrews, J. Meddings, O. Suchowersky
}

\begin{abstract}
Although it is now generally recognized that the clinical spectrum of Parkinson disease (PD) is broader than its defining motor aspects, its various non-motor symptoms are often not routinely assessed in the clinical setting. As most of these symptoms are amenable to treatment, improved recognition would lead to more comprehensive management of the disease, and ultimately improve the quality of life for PD patients. In an attempt to increase the general awareness of physicians caring for these patients, this article focuses on the clinical manifestations and treatment of the gastrointestinal symptoms most commonly experienced by PD patients, as well as on the gastrointestinal side effects of antiparkinsonian treatments.
\end{abstract}

\begin{abstract}
RÉSUMÉ: Symptômes gastrointestinaux dans la maladie de Parkinson : aspects cliniques et traitement. Bien qu'il soit maintenant bien connu que le spectre clinique de la maladie de Parkinson (MP) soit plus large que les aspects moteurs qui le définissent, l'évaluation des symptômes non moteurs n'est souvent pas faite de routine en clinique. Comme la plupart de ces symptômes sont traitables, une recherche plus systématique de ces symptômes entraînera une prise en charge plus globale de la maladie et ainsi une meilleure qualité de vie pour les patients atteints de la MP. Cet article traite des manifestations cliniques et du traitement des symptômes gastrointestinaux les plus fréquents chez ces patients ainsi que des effets gastrointestinaux des médicaments antiparkinsoniens, afin de sensibiliser sur ce sujet les médecins qui traitent ces patients.
\end{abstract}

Can. J. Neurol. Sci. 2011; 38: 557-564

Parkinson's disease (PD), which consistently accounts for over $80 \%$ of the cases of neurodegenerative parkinsonism reported in the medical literature ${ }^{1-3}$, is currently diagnosed using the United Kingdom (UK) Parkinson's Disease Society Brain Bank clinical diagnostic criteria ${ }^{4}$. As early as 1817 James Parkinson acknowledged in his An essay on the shaking palsy that the clinical spectrum of PD is much broader, encompassing many non-motor symptoms ${ }^{5}$, among which gastrointestinal complaints are one of the most common ${ }^{6-8}$.

In the clinical setting gastrointestinal complaints are generally not regarded to be significant, and are often not systematically addressed ${ }^{9,10}$. However, it has been well documented that gastrointestinal symptoms are prevalent, bothersome, may appear at a very early stage of the disease, and harbor a high potential to adversely impact patients' quality of life ${ }^{11}$.

The purpose of this article is to review the clinical manifestations and treatment of gastrointestinal symptoms commonly experienced by patients with PD, as well as the gastrointestinal side effects of antiparkinsonian treatments. Related issues, such as the neural control of gastrointestinal function and an overview of the pathophysiology of the various gastrointestinal symptoms, lie beyond the scope of this review.
Interested readers are referred to relevant publications, where they have been extensively addressed ${ }^{12-18}$.

\section{The clinical spectrum of gastrointestinal symptoms in PD}

\section{Drooling}

Drooling is reported by $32-74 \%$ of PD patients depending on the symptom definition used, and increases with the severity of PD. A recent review by Kalf et $\mathrm{al}^{19}$ estimates an overall prevalence of $56 \%$, with the symptom rated as frequent in 22$26 \%$ of patients. Drooling is often a source of embarrassment and may lead to the social isolation of many patients ${ }^{20}$.

From the Movement Disorders Program, Department of Clinical Neurosciences (DSF OS), Division of Gastroenterology, Department of Internal Medicine (CNA, JM), University of Calgary, Calgary; Department of Medicine (Neurology) and Medical Genetics (OS), University of Alberta, Edmonton, Alberta, Canada.

Received October 28, 2010. Final Revisions Submitted February 10, 2011. Correspondence to: David Salat-Foix, Movement Disorders Program. Department of Clinical Neurosciences, Area 3, UCMC, 3350 Hospital Drive NW, Calgary, Alberta, T2N 4N1, Canada. 
In the beginning drooling tends to occur only during sleep hours and gradually extends throughout the daytime, starting in periods when the patient is fully relaxed or is about to engage in complex motor activities. In terms of severity, it is generally agreed that the amount of drooling correlates with the overall severity of the disease. For reasons that are not well understood, some reports in the literature have found gender differences, with men being more affected than women.

The output of saliva is usually normal or minimally reduced in PD. Drooling is mainly a consequence of motor impairment, mostly due to hypokinesia of the pharyngeal muscles and loss of the involuntary swallowing reflex.

The first steps in the treatment of drooling should be to explain the nature of this symptom to the patient and to optimize control of the motor aspects of the disease. Behavioral interventions and physiotherapy have been tried (although not specifically in a PD patient population), and have usually met with a low rate of success ${ }^{21}$. A recent study by South et $\mathrm{al}^{22}$, however, suggests that a simple intervention such as chewing gum can modify the swallowing frequency and latency, and thus may have a potential to improve drooling.

Anticholinergic drugs have been used to treat drooling in PD patients. Systemically glycopyrrolate (administered as $1 \mathrm{mg}$ three times daily) is preferred by some authors due to its lower potential to cross the blood-brain barrier ${ }^{23}$ ). Locally, sublingual atropine drops $(0.5 \mathrm{mg} \text { twice daily })^{24}$ or ipratropium bromide spray (one or two $21 \mu \mathrm{g}$ puffs up to four times a day) ${ }^{25}$ may be helpful. Although they should be used cautiously in PD patients, usually an aged population that may be prone to the development of cognitive and autonomic side effects, it should be noted that drugs that have anticholinergic side-effects (such as amitryptiline ${ }^{26}$ or amantadine) can also be used to treat drooling. The efficacy of other drugs, such as modafinil (100 mg daily $)^{27}$ and clonazepam has been anecdotally reported.

If these approaches fail, injection of the parotid and/or the submandibular glands with botulinum toxin can be performed $^{28,29}$. Type A toxin is most often used at a starting dose of 30-100U. Its effect can be noted within 48-72 hours, peaking by the 14th day after the injection, and the benefit may last for up to 30 weeks. Subsequent injection sites and doses need to be determined according to previous results. Besides the usual side effects of botulinum toxin, attention must be paid to avoiding an excessive decrease in saliva output, as this may result in worsening of dysphagia.

Although not formally evaluated in PD patients, severe cases of drooling may be managed with aggressive strategies, such as radiotherapy ${ }^{30}$, submandibular duct relocation, or transtympanic neurectomy ${ }^{31}$.

\section{Dysphagia}

Dysphagia is defined as the disturbance of the passage of ingested substances through the esophagus. Parkinson's disease is the most frequent neurological cause of dysphagia, affecting up to $85 \%$ of patients with advanced disease ${ }^{32}$. In addition to patient distress ${ }^{33}$, dysphagia may lead to weight loss and severe respiratory tract infections (odds ratios up to five times higher than age-matched healthy subjects). Aspiration pneumonia is among the most frequent causes of death of these patients.
Dysphagia can present itself either in the "on" phase, related to cervicocranial dyskinesia, or in the "off" phase, related to rigidity and hypokinesia of the muscles involved in swallowing ${ }^{34}$. An additional potential cause for dysphagia is the loss of coordination of this complex activity which could result from brainstem involvement by the disease process ${ }^{12}$.

Objective testing has shown that dysphagia can be due to malfunction of any of the structures involved in swallowing, from the mouth to the esophagus, either from direct involvement or from that of the neural centers that control them. By manometric testing, the most frequent abnormalities are decreased resting pressure of the upper esophageal sphincter, decreased peak pharyngeal contraction pressure, slow pharyngeal transport, and abnormal esophageal peristalsis (most often aperistalsis or diffuse esophageal spasm) $)^{35}$. Videofluoroscopic assessment shows slowing of the oropharyngeal phases, abnormal tongue motion, multiple attempts to swallow after a single ingestion, delayed laryngeal elevation, incomplete esophageal transit, and abnormal esophageal peristalsis ${ }^{36}$. Food residues can be seen in multiple sites (tongue, anterior and lateral sulci, valleculae, and pyriform sinuses). Electrophysiological tests disclose a prolonged swallowing reflex latency and extreme lengthening of the pharyngeal reflex time ${ }^{37}$. Abnormal findings tend to correlate with the frequency of symptoms and are found in $75 \%$ of overall PD patient population, but in as many as $90 \%$ of those who have daily symptoms, irrespective of PD severity. Some of these abnormalities may be found in aging populations, so the exact relationship that they may bear to PD is hard to determine ${ }^{38}$.

Patients' symptoms of dysphagia may not correlate with objective findings of abnormal deglutitative function, and viceversa. Sung et $\mathrm{al}^{39}$ recently studied the prevalence of dysphagiaassociated symptoms in 54 treatment-naïve patients with early PD. The sensation of "getting stuck" (31.5\%), fragmented deglutition (29.6\%), choking (27.8\%), globus (16.7\%), and odynophagia $(5.6 \%)$ were commonly reported. However, there was no statistically significant correlation between impedance/ manometry testing findings and symptoms.

Due to the common finding of non-specific esophageal motility abnormalities even in healthy populations, objective testing is only recommended in symptomatic patients or those with a clinical suspicion of pulmonary aspiration. For those with predominantly oropharyngeal symptoms (such as coughing, choking, or difficulty initiating swallows) videofluoroscopic evaluation with a modified barium swallow and/or speech/ language pathologist assessment is ideal. Patients with esophageal symptoms such as retrosternal dysphagia may benefit from esophageal manometry or barium esophagram.

Since dysphagia is among the non-motor symptoms that respond poorly to dopaminergic treatment ${ }^{40}$, management is largely directed at minimizing the risk of aspiration. Standard recommendations include eating while in the "on" phase, in a sitting position and tilting the head slightly downwards. The patient should avoid foods of mixed textures, use fluid thickening preparations, take small bites, and gently cough after each swallow. However, the efficacy of these maneuvers has not been firmly established in the medical literature ${ }^{41}$, and a more comprehensive evaluation by a speech therapist may be necessary. For patients with a significant dysfunction of the upper esophageal sphincter, specific treatment with either the 
injection of botulinum toxin type A (30 units in each muscle $)^{42}$ or myotomy ${ }^{43}$ have been described in small case series. However, these procedures may increase aspiration risk in PD patients with impairment of other components of their swallowing mechanism. In severe cases, feeding by nasogastric tube or a gastrostomy may be required ${ }^{44}$.

\section{Dyspepsia}

A case-control study of 98 PD patients and 50 controls showed significantly higher reports of nausea ( $25 \%$ vs $8 \%$ ), and a trend toward increased early satiety, bloating, vomiting and heartburn ${ }^{45}$. These symptoms are likely multifactorial in origin due to both the disease process and the effect of dopaminergic medication.

Measurement of gastric emptying by scintigraphy has suggested slower emptying in patients with early disease on levodopa, but moderately severe PD patients in the "on" phase may have normal emptying ${ }^{46}$. In patients with advanced disease, both erratic or impaired gastric emptying and the interference of proteins on drug absorption contribute to variable bioavailability of L-Dopa ${ }^{47-49}$. This has been linked to the development of motor complications such as the "delayed-on" and "no-on" phenomena, or dyskinesias.

Because of the lack of specificity of dyspepsia symptoms in general, the presence of "alarm" features such as persistent vomiting, evidence of gastrointestinal bleeding or anemia, abdominal mass, unexplained weight loss, or dysphagia should prompt further evaluation to rule out alternative diagnoses ${ }^{50}$.

General dietary advice is difficult, because dietary triggers for dyspepsia vary widely and inconsistently, but identified problem foods should be avoided. However, overly restrictive diets should be discouraged due to a risk of malnourishment among PD patients. Prokinetic drugs are the mainstay of treatment for dyspepsia, with domperidone $10-20 \mathrm{mg}$ orally up to four times daily being the preferred choice since it does not cross the bloodbrain barrier and has minimal, if any, central antidopaminergic effects $^{51}$. Aggressive treatment for severe gastric emtpying, such as pyloric botulinum toxin A injection or gastric neurostimulation $^{52}$ have not been evaluated in PD patients and should only be considered after evaluation by a gut motility specialist.

There are no specific guidelines for the management of motor complications related to the alteration of gastric emptying. Personal experiences such as that of Nyholm and Lennernäs ${ }^{48}$ suggest that not taking the dopaminergic drugs during proteinrich meals or taking them with certain products (in their series chocolate, bananas, coffee or carbonated beverages) may be beneficial; in case these dietary measures fail, dopaminergic stimulation in any of its available modes should be tailored, according to clinical experience and local availability, to achieve maximal response with minimal side-effects.

The influence of Helicobacter pylori infection on the derangement of L-dopa absorption has been suggested in various studies. Decreased drug absorption and effect (which is both delayed and shortened) have been documented in infected patients ${ }^{53}$, and these abnormalities can be reversed by successful eradication of the bacteria ${ }^{54}$. Although the precise nature of this relationship remains elusive, uptake and utilization of levodopa by Helicobacter pylori has been proposed as an explanation for this observation ${ }^{55}$.

\section{Constipation}

Constipation is a functional bowel disorder that presents as persistently difficult, infrequent, or seemingly incomplete defecation. Formally, it must include at least two of: straining, lumpy or hard stools, sensation of incomplete evacuation or anorectal obstruction, need for manual facilitating maneuvers, or fewer than three defecations per week ${ }^{56}$.

Large population-based studies such as the Honolulu Asia Aging Study ${ }^{57}$ have documented that a low frequency of bowel movements is associated with a three-fold increased risk of developing PD over a ten year follow-up period, and that, on average, constipation precedes the onset of motor symptoms by 12 years. A recent case-control study from Olmsted County (Minnesota, USA $)^{58}$ evaluated constipation in a populationbased sample of incident PD cases and found that constipation was diagnosed in $36.2 \%$ of patients who subsequently developed PD but only $20.4 \%$ of the control group (odds ratio $2.48,95 \% \mathrm{CI}$ 1.2-3.34, p 0.008). This finding remained significant after adjustment for confounding factors such as smoking and coffee consumption, and was more robust when constipation developed over 20 years before the onset of motor symptoms. Moreover, incidental Lewy bodies or decreased cellular density in the substantia nigra at autopsy of constipated patients with no parkinsonian symptoms has been also reported ${ }^{59,60}$.

Series from specialist referral clinics suggest that the prevalence of constipation among PD patients is high, with $59 \%$ of consecutive PD patients referred to a movement disorders clinic reporting the symptom vs. $21 \%$ in a control group of individuals aged over $65^{61}$. Constipation has been related to aging, so it is worth noting that this study found no significant association to the age at diagnosis of PD, suggesting that constipation and PD are not associated through the possible confounding effect of age. In a large survey study which used a validated constipation score only $7 \%$ of the patients had "severe" symptoms ${ }^{62}$. The nature of the symptoms, considered to be a source of dissatisfaction by as many as $45-60 \%$ of PD patients, has been evaluated by Sakakibara et $\mathrm{l}^{63}$, who have made an interesting distinction between the early phase, in which mostly reduced number of bowel movements are encountered (20-81\% vs. $0-33 \%$ of healthy age-matched persons), and the later stages, in which difficulty in defecation is more frequently encountered (57-67\% vs. 26-28\%). Parkinson disease patients typically have multiple symptoms related to constipation, among which unsuccessful defecation attempts and the sensation of incomplete emptying are associated to the severity of PD, and decreased frequency of bowel movements is associated with a longer time since diagnosis ${ }^{62}$.

Objective measurement of colon neuromuscular function in PD has shown decreased colonic motility, with longer mean colonic transit times as compared to healthy controls (44-130 hours vs. 20-39 hours) ${ }^{64}$. Since an association with abnormal parasympathetic function (such as an increase in R-R variability on electrocardiogram (EKG) recordings) has been described in PD patients ${ }^{65}$, constipation may be a manifestation of the involvement of this system by the disease process.

Anecdotal reports in the medical literature of patients with an acute dysmotilty presentation (such as pseudo-obstruction, paralytic ileus, or Ogilvie's syndrome) are likely more related to 
metabolic derangements or complications of antiparkinsonian treatments than to the disease itself.

Management of constipation in PD is identical to other causes of constipation. Although their benefit has not been proven in controlled studies, the initial steps are to increase dietary fiber intake, avoid dehydration, and increase exercise. In case these initial measures fail, bulk-forming laxatives (such as psyllium ${ }^{66}$ ) or osmotic laxatives (such as milk of magnesia or polyethylene glycol ${ }^{67}$ ) are the mainstay of treatment. The use of stimulant laxatives such as bisacodyl or senna are common, but are not recommended for long-term use due to colonic habituation.

Domperidone, which is highly effective in the proximal gastrointestinal tract, has minimal effect on colonic function ${ }^{68}$. Serotoninergic drugs such as mosapride, tegaserod and cisapride have a prokinetic effect that can improve constipation without worsening parkinsonian symptoms, but in most countries these agents have been removed from the market due to risk of cardiac arrhythmia. Cisapride ${ }^{69}$ is available for compassionate use through Health Canada. Refractory cases may be managed by the addition of the prostaglandin E1 analogue misoprostol (600$2400 \mu \mathrm{g}$ daily) to a conventional therapeutic regime, although patient intolerance and loss of effectiveness over time seriously limit its long-term use $\mathrm{e}^{70}$. There have been reports on a potential benefit of other drugs, such as erythromycin or colchicine, but there is currently not enough evidence to recommend their use. Functional magnetic stimulation of the thoracic and lumbosacral nerves by placing a coil on the T9 and L3 spinal processes in 20 minute twice-daily sessions for three weeks ${ }^{71}$ has been proposed as an alternative, and found to significantly accelerate colonic transit and improve all the aspects of defecation for as long as the three month follow-up period of the study.

In a subset of patients complaining of constipation this symptom is not related to slowed intestinal transit, but to inability to expel stool due to disordered defecation. In these patients paradoxical contraction of the puborectal muscles and of the external anal sphincter during attempted defecation can be documented by electromyogram (EMG) recording, and this has been suggested to represent a focal dystonia ${ }^{72}$. However, a more recent report in which anal manometry was performed in a series of PD patients with lower gastrointestinal complaints, however, found that in those with a defecation disorder, a failure of anal relaxation was more common than paradoxical contraction ${ }^{73}$.

An effort to relate the defecatory abnormalities to the "on" or "off" phase should be made, in order to determine the appropriate therapy. If it felt to be part of the "off" phenomenology, optimization of the dopaminergic regime is required, and apomorphine has occasionally been found to be most effective in this situation ${ }^{74}$. Treatment with pelvic floor physiotherapy or biofeedback retraining ${ }^{75,76}$ has good long-term efficacy and the added benefit of being minimally invasive with no adverse effects. For refractory cases, injections of botulinum toxin A into anal sphincters or puborectalis muscles ${ }^{77,78}$, transanal irrigation, or colostomy have been used ${ }^{79}$.

\section{Abdominal pain}

Bouts of excruciating abdominal pain are occasionally reported by PD patients. These generally occur during the "off" phase, and are thought to be a part of a central pain syndrome, possibly related to dysfunction of the spinoreticulothalamic pathways and their connections. Epidemiological studies on this symptom are scarce in the medical literature. Twenty-two percent of patients (as compared to $18 \%$ of controls) were found to have abdominal pain in one case-control study ${ }^{45}$. The most useful clinical clues for its diagnosis are an intermittent course and a relation to the "off" phase.

If no other cause for the abdominal pain is found, the first step in its management should be to explain its cause to the patients and their families, and the optimization of the dopaminergic treatment. In more severe cases, symptomatic relief can be obtained by the use of analgesics, either conventional or opioid-derived agents, tricyclic antidepressants or atypical neuroleptics ${ }^{80}$.

\section{Fecal incontinence}

Although fecal incontinence is thought to occur in less than $10 \%$ of PD patients, its impact on quality of life measures in usually marked.

In a very small series of PD patients evaluated with anal manometry, Stocchi et $\mathrm{al}^{73}$ found a $5.9 \%$ prevalence of incontinence for solid feces, but reported an overall prevalence of $41 \%$ if incontinence for liquid feces (most often after laxatives had been taken to treat constipation) was included. Decreased mean resting and maximal contraction anal pressures were documented by anal manometry. Both incontinence and the manometric findings correlated with age and disease duration. No specific guidelines for therapy in PD patients are found in the literature, and given the low frequency with which it is encountered, referral to a gastroenterologist would be appropriate. Management of neurogenic fecal incontinence should start with conservative measures such as modification of stool consistency and bowel training. Pelvic floor strengthening exercises and/or biofeedback have been shown to be beneficial in the non-PD population ${ }^{81}$, and would likely be applicable to PD patients. Loperamide to slow down bowel movement frequency is another commonly-used therapy for fecal incontinence. However, as it may substantially increase the risk of constipation in the PD population, it should be used cautiously. Sacral nerve stimulation $^{82}$ has emerged as a minimally invasive, effective and well tolerated treatment option.

Table 1: Prevalence of gastrointestinal side-effects of selected dopaminergic drugs. Adapted from Kulisevsky et $\mathbf{a l}^{83}$.

\begin{tabular}{l|c|c|c|c|c}
\hline & L-Dopa & DA & pramipexole & ropirinole & placebo \\
& general & & & \\
\hline Nausea & $27 \%$ & $21 \%$ & $20 \%$ & $27 \%$ & $14 \%$ \\
\hline Vomiting & $6 \%$ & $6 \%$ & $5 \%$ & $6 \%$ & $3 \%$ \\
\hline Abd pain & $10 \%$ & $6 \%$ & $8 \%$ & $6 \%$ & $4 \%$ \\
\hline
\end{tabular}

DA, dopamine agonists: Abd pain, abdominal pain 


\section{Gastrointestinal side effects of antiparkinsonian drugs}

Gastrointestinal complaints are among the most frequent side effects of antiparkinsonian drugs, and can be expected in over $25 \%$ of the patients taking them. However, it should be noted that both their prevalence and severity tend to decrease over time, and are usually responsive to symptomatic therapy.

A recent meta-analysis ${ }^{83}$ reported on the frequency of various gastrointestinal side effects (including nausea, vomiting, constipation, and abdominal pain) of both L-Dopa and dopamine agonists. Except for abdominal pain, all of these side effects were found to be significantly more prevalent among patients taking dopaminergic drugs compared to placebo, and are summarized in Table 1. The potential development or worsening of nausea and constipation associated with the initiation of LDopa therapy is worth mentioning to patients, in order to avoid the unnecessary concern that can arise if they are unaware of this possible relationship. Starting dopaminergic treatment with a low dose and titrating upwards slowly as needed ("start low, go slow") improves the gastrointestinal tolerance of these drugs.

The addition of entacapone to an L-Dopa based treatment regime has the potential to increase the prevalence and severity of side effects, such as nausea and vomiting. In a clinical trial of these agents, nausea was reported by $13.5 \%$ of patients taking LDopa/carbidopa, and by $26.6 \%$ of those taking L-Dopa/ carbidopa/entacapone; however the drop-out rate for this symptom was similar in both groups ${ }^{84}$. Diarrhea is a well known side effect of entacapone, not commonly seen with other antiparkinsonian drugs. It occurred in $8.7 \%$ of the patients in the treatment group compared to $2.8 \%$ of patients on LDopa/carbidopa alone, and was severe enough as to lead to the drop-out from the study in $3.9 \%$ of the patients.

Rasagiline appears to have minimal gastrointestinal side effects based on a comprehensive review by Chen et $\mathrm{al}^{85}$. However, in the PRESTO study (in which rasagiline $(0.5 \mathrm{mg} /$ day or $1 \mathrm{mg} /$ day) or placebo were added during 26 weeks to the levodopa/carbidopa treatment of 472 moderate to advanced PD patients with motor fluctuations) the incidence of vomiting was higher with the drug than with placebo $(3.7 \%$ in patients taking $0.5 \mathrm{mg} /$ day and $6.7 \%$ in patients taking $1 \mathrm{mg} /$ day vs. $1.3 \%$ in the placebo group).

The gastrointestinal side-effects of amantadine are thought to be largely due to their anticholinergic properties. Nausea has been reported in 5-10\%, anorexia, constipation, diarrhea, and dry mouth in $1-5 \%$, and vomiting in up to $1 \%$ of patients taking this medication $^{86}$.

Table 2: Summary of treatment options for each gastrointestinal symptom, their level of evidence and grade of recommendation (as issued by the Quality Standards Subcommittee of the AAN ${ }^{89}$ and the EFNS/MDS-ES Joint Task Force $^{90}$ ), and list of relevant references used for this review

\begin{tabular}{|c|c|c|c|c|}
\hline Symptom & Treatment options & $\mathrm{LE}^{87}$ & $\mathrm{GR}^{88}$ & Ref \\
\hline Drooling & $\begin{array}{l}\text { 1. Optimize dopaminergic treatment } \\
\text { 2. Behavioral and physical therapy: gum chewing and others } \\
\text { 3. Anticholinergic drugs: glycopyrrolate } \\
\text { sublingual atropine drops } \\
\text { ipratropium bromide puffs } \\
\text { 4. Other pharmacological options: amitriptiline } \\
\text { modafinil, } \\
\text { amantadine, clonazepam } \\
\text { 5. Parotid and/or submandibular gland botulinum toxin injection } \\
\text { 6. Radiotherapy, surgery (for resistant cases) }\end{array}$ & $\begin{array}{l}- \\
\text { III } \\
\text { III } \\
\text { IV } \\
\text { III } \\
\text { IV } \\
\text { IV } \\
- \\
\text { I } \\
\text { IV }\end{array}$ & $\begin{array}{l}- \\
U \\
U \\
U \\
U \\
U \\
U \\
- \\
\text { A } \\
\text { U }\end{array}$ & $\begin{array}{l}- \\
22 \\
23 \\
24 \\
25 \\
26 \\
27 \\
- \\
28,29 \\
30\end{array}$ \\
\hline Dysphagia & $\begin{array}{l}\text { 1. Swallowing training and diet texture modification to prevent aspiration } \\
\text { 2. Cricopharyngeal botulinum toxin injection } \\
\text { or myotomy (if UES significantly involved) } \\
\text { 3. Tube feeding (in severe, unresponsive cases) }\end{array}$ & $\begin{array}{l}- \\
\text { IV } \\
\text { IV }\end{array}$ & $\begin{array}{l}- \\
U \\
U\end{array}$ & $\begin{array}{l}- \\
42 \\
43 \\
44\end{array}$ \\
\hline Dyspepsia & $\begin{array}{l}\text { 1. Prokinetic drugs: domperidone preferred } \\
\text { 2. Pylorus botulinum toxin A injection or gastric pacemaker implantation (for severe cases) } \\
\text { 3. Consider eradication for Helicobacter pylori infected fluctuating patients }\end{array}$ & $\begin{array}{l}\text { II } \\
\text { IV } \\
\text { IV }\end{array}$ & $\stackrel{B}{U}[88]$ & $\begin{array}{l}51 \\
52 \\
54\end{array}$ \\
\hline Constipation & $\begin{array}{l}\text { 1. Fiber-rich diet, abundant fluid intake, increase exercise } \\
\text { 2. Bulk-forming laxatives: psyllium, } \\
\text { polyethylene glycol } \\
\text { 3. Prokinetic drugs: cisapride }{ }^{a} \\
\text { 4. Other pharmacological approaches:misoprostol (as add-on to conventional regime) } \\
\text { erythromycin, colchicine } \\
\text { 5. Functional magnetic stimulation of thoraco-lumbar nerves }\end{array}$ & $\begin{array}{l}- \\
\text { III } \\
\text { II } \\
\text { III } \\
\text { IV } \\
-\end{array}$ & $\begin{array}{l}- \\
U \\
U \\
U \\
- \\
U\end{array}$ & $\begin{array}{l}- \\
66 \\
67 \\
69 \\
70 \\
- \\
71\end{array}$ \\
\hline $\begin{array}{l}\text { Puborectal } \\
\text { dystonia }\end{array}$ & $\begin{array}{l}\text { 1. Optimize dopaminergic treatment if related to off phase } \\
\text { (apomorphine may be especially effective) } \\
\text { 2. Biofeedback retraining } \\
\text { 3. Puborectalis botulin toxin A injection } \\
\text { 4. Trans-anal or anterograde colonic irrigation, colostomy }\end{array}$ & $\begin{array}{l}- \\
\text { IV } \\
\text { III } \\
\text { III } \\
\text { IV }\end{array}$ & $\begin{array}{l}- \\
U \\
U \\
U\end{array}$ & $\begin{array}{c}- \\
74 \\
75,76 \\
77 \\
79\end{array}$ \\
\hline $\begin{array}{l}\text { Abdominal } \\
\text { pain }\end{array}$ & $\begin{array}{l}\text { 1. Optimize dopaminergic treatment } \\
\text { 2. Symptomatic treatment: conventional or opioid-derived analgesics, tricyclic antidepressants, } \\
\text { atypical neuroleptics }\end{array}$ & IV & $\bar{u}$ & 80 \\
\hline $\begin{array}{l}\text { Fecal } \\
\text { incontinence }\end{array}$ & $\begin{array}{l}\text { 1. Stool consistency modification, bowel training } \\
\text { 2. Sacral nerve stimulation } \\
\text { 3. Trans-anal or anterograde colonic irrigation, colostomy }\end{array}$ & $\begin{array}{l}- \\
\text { IV } \\
\text { IV }\end{array}$ & $\begin{array}{l}- \\
U\end{array}$ & $\begin{array}{l}- \\
82 \\
79\end{array}$ \\
\hline
\end{tabular}

LE, level of evidence; GR, grade of recommendation, Ref, reference, UES, upper esophageal sphincter; A, established as effective; B, probably effective; C, possibly effective; U, current data inadequate or conflicting. ${ }^{\text {a }}$ only available for compassionate use through Health Canada. 
Anticholinergic medications are not frequently used to treat PD in North America, but they are worth mentioning because of their specific gastrointestinal side effects, among which dry mouth (which could actually be beneficial for patients with drooling) and a 30-50\% chance of worsening constipation are the most significant. Worsening of constipation caused by anticholinergic treatment is almost the only circumstance in which constipation in PD can lead to serious complications, such as extreme colonic dilatation or perforation.

\section{CONCLUSION}

Parkinson's disease, the second most prevalent neurodegenerative disease, is mostly recognized by its motor manifestations. The clinical spectrum of the disease, however, is much broader and encompasses many non-motor symptoms, among which gastrointestinal complaints are a frequent source of discomfort and health risks for patients with this condition. These symptoms include drooling, dysphagia, dyspepsia, constipation, abdominal pain, and fecal incontinence.

Although the symptoms may present very early in the course of the disease, their prevalence, severity and impact on the patients' quality of life usually increase as the disease progresses.

The correlation between subjective complaints and objective findings on formal testing of the gastrointestinal tract is often poor, so the decision to undertake any ancillary testing should be guided primarily by concerns about serious complications (especially aspiration in the case of dysphagia) or alternative underlying causes for a given symptom (eg. dyspepsia in the presence of "alarm symptoms").

The management of these symptoms among PD patients does not differ significantly from what is recommended to treat them in the general population, except for the fact that drugs with a known potential to worsen extra-pyramidal signs (such as metoclopramide) or to which PD patients may be exquisitely sensitive (such as those with an anticholinergic effect) should be avoided. A summary of therapeutic options for each of the reviewed symptoms is provided in Table 2 .

Gastrointestinal complaints (including nausea, vomiting, constipation, and abdominal pain) can be expected in over $25 \%$ of the patients taking antiparkinsonian drugs, although they tend to decrease over time, and are usually responsive to symptomatic therapy. Diarrhea is a potential side effect of entacapone, not commonly seen with other antiparkinsonian drugs. Drugs with an anticholinergic effect must be used cautiously, because worsening constipation in this setting may lead to serious complications, such as extreme colonic dilatation or perforation.

\section{REFERENCES}

1. Bower JH, Maraganore DM, McDonnell SK, Rocca WA. Incidence and distribution of parkinsonism in Olmsted County, Minnesota, 1976-1990. Neurology. 1999 Apr 12;52(6):1214-20.

2. Benito-León J, Bermejo-Pareja F, Morales-González JM, et al. on behalf of the Neurological Disorders in Central Spain (NEDICES) Study Group. Incidence of Parkinson disease and parkinsonism in three elderly populations of central Spain. Neurology. 2004 Mar 9;62(5):734-41.

3. Linder $J$, Stenlund $H$, Forsgren L. Incidence of PD and parkinsonism in northern Sweden: a population-based study. Mov Disord. 2010 Feb 15;25(3):341-8.

4. Hughes AJ, Daniel SE, Kilford L, Lees AJ. Accuracy of clinical diagnosis of idiopathic Parkinson's disease: a clinico- pathological study of 100 cases. J Neurol Neurosurg Psychiatry. 1992 Mar;55(3):181-4.

5. Muzerengi S, Contrafatto D, Chaudhuri KR. Non-motor symptoms: identification and management. Parkinsonism Relat Disord. 2007;13 Suppl 3:S450-6.

6. Pfeiffer RF. Gastrointestinal dysfunction in Parkinson's disease. Lancet Neurol. 2003 Feb;2(2):107-16.

7. Natale G, Pasquali L, Ruggieri S, et al. Parkinson's disease and the gut: a well known clinical association in need of an effective cure and explanation. Neurogastroenterol Motil. $2008 \mathrm{Jul} ; 20$ (7): 741-9.

8. Jost WH. Gastrointestinal dysfunction in Parkinson's Disease. J Neurol Sci. 2010 Feb 15;289(1-2):69-73.

9. Stacy M, Bowron A, Guttman M, et al. Identification of motor and nonmotor wearing-off in Parkinson's disease: comparison of a patient questionnaire versus a clinician assessment. Mov Disord. 2005 Jun;20(6):726-33.

10. Chaudhuri KR, Prieto-Jurcynska C, Naidu Y, et al. The nondeclaration of nonmotor symptoms of Parkinson's disease to health care professionals: an international study using the nonmotor symptoms questionnaire. Mov Disord. 2010 Apr 30; 25(6):697-701.

11. Kyle G. The physical, social and emotional effects of bowel dysfunction in Parkinson's disease. Nurs Times. 2010 Aug 2430;106(33):20-2.

12. Cersosimo MG, Benarroch EE. Neural control of the gastrointestinal tract: implications for Parkinson disease. Mov Disord. 2008 Jun 15;23(8):1065-75.

13. Dickson DW, Braak H, Duda JE, et al. Neuropathological assessment of PD: refining the diagnostic criteria. Lancet Neurol. 2009 Dec;8(12):1150-7.

14. Braak H, Rüb U, Gai WP, Del Tredici K. Idiopathic PD: possible routes by which vulnerable neuronal types may be subject to neuroinvasion by an unknown pathogen. J Neural Transm. 2003 May;110(5):517-36.

15. Braak H, de Vos RA, Bohl J, Del Tredici K. Gastric alpha-synuclein immunoreactive inclusions in Meissner's and Auerbach's plexuses in cases staged for PD-related brain pathology. Neurosci Lett. 2006 Mar 20;396(1):67-72.

16. Greene JG, Noorian AR, Srinivasan S. Delayed gastric emptying and enteric nervous system dysfunction in the rotenone model of PD. Exp Neurol. 2009 Jul;218(1):154-61.

17. Drolet RE, Cannon JR, Montero L, Greenamyre JT. Chronic rotenone exposure reproduces PD gastrointestinal neuropathology. Neurobiol Dis. 2009 Oct;36(1):96-102.

18. Blandini F, Balestra B, Levandis G, et al. Functional and neurochemical changes of the gastrointestinal tract in a rodent model of PD. Neurosci Lett. 2009 Dec 31;467(3):203-7.

19. Kalf JG, de Swart BJ, Borm GF, et al. Prevalence and definition of drooling in PD: a systematic review. J Neurol. 2009 Sep;256(9): 1391-6. Epub 2009 Mar 14.

20. Kalf JG, Smit AM, Bloem BR, et al. Impact of drooling in PD. J Neurol. 2007 Sep;254(9):1227-32.

21. van der Burg JJ, Didden R, Jongerius PH, Rotteveel JJ. A descriptive analysis of studies on behavioural treatment of drooling (1970-2005). Dev Med Child Neurol. 2007 May;49(5): 390-4.

22. South AR, Somers SM, Jog MS. Gum chewing improves swallow frequency and latency in Parkinson patients: A preliminary study. Neurology. 2010;74;1198-202.

23. Arbouw ME, Movig KL, Koopmann M, et al. Glycopyrrolate for sialorrhea in Parkinson disease: a randomized, double-blind, crossover trial. Neurology. 2010 Apr 13;74(15):1203-7.

24. Hyson HC, Johnson AM, Jog MS. Sublingual atropine for sialorrhea secondary to parkinsonism: a pilot study. Mov Disord. 2002 Nov; 17(6): 1318-20.

25. Thomsen TR, Galpern WR, Asante A, et al. Ipratropium bromide spray as treatment for sialorrhea in Parkinson's disease. Mov Disord. 2007 Nov 15;22(15):2268-73.

26. Praharaj SK, Arora M. Amitriptyline for clozapine-induced nocturnal enuresis and sialorrhoea. Br J Clin Pharmacol. 2007 Jan;63(1):128-9. 
27. Kushnir M. Eilam A. Heldman E. Modafinil reduces drooling in Parkinson's disease. Mov Disord 2006; 21 Suppl 13: S598-9.

28. Lipp A, Trottenberg T, Schink T, et al. A randomized trial of botulinum toxin A for treatment of drooling. Neurology. 2003 Nov 11;61(9):1279-81.

29. Ondo WG, Hunter C, Moore W. A double-blind placebo-controlled trial of botulinum toxin B for sialorrhea in Parkinson's disease. Neurology. 2004 Jan 13;62(1):37-40.

30. Postma AG, Heesters M, van Laar T. Radiotherapy to the salivary glands as treatment of sialorrhea in patients with parkinsonism. Mov Disord. 2007 Dec;22(16):2430-5.

31. Meningaud JP, Pitak-Amnop P, Chikhani L, et al. Drooling of saliva: a review of the etiology and management options. Oral Surg Oral Med Oral Pathol Oral Radiol Endod 2006; 101:48-57.

32. Miller N, Allcock L, Hildreth AJ, et al. Swallowing problems in Parkinson disease: frequency and clinical correlates. J Neurol Neurosurg Psychiatry. 2009 Sep;80(9):1047-9.

33. Plowman-Prine EK, Sapienza CM, Okun MS, et al. The relationship between quality of life and swallowing in PD. Mov Disord. 2009 Jul 15;24(9):1352-8.

34. González-Fernández J, Prieto-Albin R, Velasco-Palacios L, et al. Digestive disorders in Parkinson's disease: dysphagia and sialorrhea. Rev Neurol. 2010 Feb 8;50 Suppl 2:S51-4.

35. Castell JA, Johnston BT, Colcher A, et al. Manometric abnormalities of the oesophagus in patients with PD. Neurogastroenterol Motil. 2001 Aug;13(4):361-4.

36. Nagaya M, Kachi T, Yamada T, Igata A. Videofluorographic study of swallowing in PD. Dysphagia. 1998 Spring;13(2):95-100.

37. Ertekin C, Tarlaci S, Aydogdu I, et al. Electrophysiological evaluation of pharyngeal phase of swallowing in patients with PD. Mov Disord. 2002 Sep;17(5):942-9.

38. Schindler JS, Kelly JH. Swallowing disorders in the elderly. Laryngoscope. 2002 Apr;112(4):589-602.

39. Sung HY, Kim JS, Lee KS, et al. The prevalence and patterns of pharyngoesophageal dysmotility in patients with early stage PD. Mov Disord. 2010 Jul 28.

40. Menezes C, Melo A. Does levodopa improve swallowing dysfunction in Parkinson's disease patients? J Clin Pharm Ther. 2009 Dec;34(6):673-6.

41. Baijens LW, Speyer R. Effects of therapy for dysphagia in PD: systematic review. Dysphagia. 2009 Mar;24(1):91-102.

42. Restivo DA, Palmeri A, Marchese-Ragona R. Botulinum toxin for cricopharyngeal dysfunction in Parkinson's disease. N Engl J Med. 2002 Apr 11;346(15):1174-5

43. Born LJ, Harned RH, Rikkers LF, et al. Cricopharyngeal dysfunction in Parkinson's disease: role in dysphagia and response to myotomy. Mov Disord. 1996 Jan;11(1):53-8.

44. White GN, O'Rourke F, Ong BS, et al. Dysphagia: causes, assessment, treatment, and management. Geriatrics. 2008 May; 63(5):15-20.

45. Edwards LL, Pfeiffer RF, Quigley EM, et al. Gastrointestinal symptoms in PD. Mov Disord. 1991;6(2):151-6.

46. Hardoff R, Sula M, Tamir A, et al. Gastric emptying time and gastric motility in patients with PD. Mov Disord. 2001 Nov;16 (6):1041-7.

47. Müller T, Erdmann C, Bremen D, et al. Impact of gastric emptying on levodopa pharmacokinetics in Parkinson disease patients. Clin Neuropharmacol. 2006 Mar-Apr;29(2):61-7.

48. Nyholm D, Lennernäs H. Irregular gastrointestinal drug absorption in PD. Expert Opin Drug Metab Toxicol. 2008 Feb;4(2): 193-203.

49. Cereda E, Barichella M, Pedrolli C, Pezzoli G. Low-protein and protein-redistribution diets for Parkinson's disease patients with motor fluctuations: a systematic review. Mov Disord. 2010 Oct 15;25(13):2021-34.

50. Veldhuyzen van Zanten SJ, Flook N, Chiba N, et al. An evidencebased approach to the management of uninvestigated dyspepsia in the era of Helicobacter pylori. Canadian Dyspepsia Working Group. CMAJ. 2000 Jun 13;162(12 Suppl):S3-23.

51. Lertxundi U, Peral J, Mora O, et al. Antidopaminergic therapy for managing comorbidities in patients with Parkinson's disease. Am J Health Syst Pharm. 2008 Mar 1;65(5):414-9.
52. Friedenberg FK, Parkman HP. Delayed gastric emptying: whom to test, how to test, and what to do. Curr Treat Options Gastroenterol. 2006 Jul;9(4):295-304.

53. Lee WY, Yoon WT, Shin HY, et al. Helicobacter pylori infection and motor fluctuations in patients with Parkinson's disease. Mov Disord. 2008 Sep 15;23(12):1696-700.

54. Pierantozzi M, Pietroiusti A, Brusa L, at al. Helicobacter pylori eradication and 1-dopa absorption in patients with PD and motor fluctuations. Neurology. 2006 Jun 27;66(12):1824-9.

55. Lyte M. Microbial endocrinology as a basis for improved L-DOPA bioavailability in Parkinson's patients treated for Helicobacter pylori. Med Hypotheses. 2010 May;74(5):895-7.

56. Longstreth GF, Thompson WG, Chey WD, et al. Functional bowel disorders. Gastroenterology. 2006 Apr;130(5):1480-91.

57. Abbott RD, Ross GW, White LR, et al. Environmental, life-style, and physical precursors of clinical Parkinson's disease: recent findings from the Honolulu-Asia Aging Study. J Neurol. 2003 Oct;250 Suppl 3:III30-9.

58. Savica R, Carlin JM, Grossardt BR, et al. Medical records documentation of constipation preceding Parkinson disease: A case-control study. Neurology. 2009 Nov 24;73(21):1752-8.

59. Abbott RD, Ross GW, Petrovitch H, et al. Bowel movement frequency in late-life and incidental Lewy bodies. Mov Disord. 2007 Aug 15;22(11):1581-6.

60. Petrovitch H, Abbott RD, Ross GW, et al. Bowel movement frequency in late-life and substantia nigra neuron density at death. Mov Disord. 2009 Feb 15;24(3):371-6.

61. Kaye J, Gage H, Kimber A, et al. Excess burden of constipation in Parkinson's disease: a pilot study. Mov Disord. 2006 Aug;21(8): $1270-3$.

62. Krogh K, Ostergaard K, Sabroe S, Laurberg S. Clinical aspects of bowel symptoms in Parkinson's disease. Acta Neurol Scand. 2008 Jan;117(1):60-4.

63. Sakakibara R, Uchiyama T, Yamanishi T, et al. Bladder and bowel dysfunction in Parkinson's disease. J Neural Transm. 2008;115 (3):443-60

64. Jost WH, Schrank B. Defecatory disorders in de novo Parkinsonians--colonic transit and electromyogram of the external anal sphincter. Wien Klin Wochenschr. 1998 Aug 21; 110(15):535-7

65. Shibata M, Morita Y, Shimizu T, et al. Cardiac parasympathetic dysfunction concurrent with cardiac sympathetic denervation in Parkinson's disease. J Neurol Sci. 2009 Jan 15;276(1-2):79-83.

66. Ashraf W, Pfeiffer RF, Park F, et al. Constipation in Parkinson's disease: objective assessment and response to psyllium. Mov Disord. 1997 Nov;12(6):946-51.

67. Zangaglia R, Martignoni E, Glorioso M, et al. Macrogol for the treatment of constipation in Parkinson's disease. A randomized placebo-controlled study. Mov Disord. 2007 Jul 15;22(9): 1239-44.

68. Soykan I, Sarosiek I, Shifflett J, et al. Effect of chronic oral domperidone therapy on gastrointestinal symptoms and gastric emptying in patients with Parkinson's disease. Mov Disord. 1997 Nov;12(6):952-7.

69. Jost WH, Schimrigk K. Long-term results with cisapride in Parkinson's disease. Mov Disord. 1997 May;12(3):423-5.

70. Roarty TP, Weber F, Soykan I, McCallum RW. Misoprostol in the treatment of chronic refractory constipation: results of a longterm open label trial. Aliment Pharmacol Ther. 1997 Dec;11(6): 1059-66.

71. Chiu CM, Wang CP, Sung WH, et al. Functional magnetic stimulation in constipation associated with Parkinson's disease. J Rehabil Med. 2009 Nov;41(13):1085-9

72. Mathers SE, Kempster PA, Swash M, Lees AJ. Constipation and paradoxical puborectalis contraction in anismus and PD: a dystonic phenomenon? J Neurol Neurosurg Psychiatry. 1988 Dec;51(12):1503-7.

73. Stocchi F, Badiali D, Vacca L, et al. Anorectal function in multiple system atrophy and Parkinson's disease. Mov Disord. 2000 Jan; 15(1):71-6.

74. Merello M, Leiguarda R. Adynamic bowel syndrome in Parkinson's disease with dramatic response to apomorphine. Clin Neuropharmacol. 17(6):574-78. 
75. Simón MA, Bueno AM. Behavioural treatment of the dyssynergic defecation in chronically constipated elderly patients: a randomized controlled trial. Appl Psychophysiol Biofeedback. 2009 Dec;34(4):273-7.

76. Rao SS, Valestin J, Brown CK, et al. Long-term efficacy of biofeedback therapy for dyssynergic defecation: randomized controlled trial. Am J Gastroenterol. 2010 Apr;105(4):890-6.

77. Ron Y, Avni Y, Lukovetski A, et al. Botulinum toxin type-A in therapy of patients with anismus. Dis Colon Rectum. 2001 Dec; 44(12):1821-6.

78. Farid M, El Monem HA, Omar W, et al. Comparative study between biofeedback retraining and botulinum neurotoxin in the treatment of anismus patients. Int J Colorectal Dis. 2009 Jan;24 (1):115-20.

79. Krogh K, Christensen P. Neurogenic colorectal and pelvic floor dysfunction. Best Pract Res Clin Gastroenterol. 2009;23(4): $531-43$

80. Ford B. Pain in Parkinson's disease. Mov Disord. 2010;25 Suppl 1:S98-103

81. Norton C, Chelvanayagam S, Wilson-Barnett J, et al. Randomized controlled trial of biofeedback for fecal incontinence. Gastroenterology. 2003 Nov;125(5):1320-9.

82. Michelsen HB, Thompson-Fawcett M, Lundby L, et al. Six years of experience with sacral nerve stimulation for fecal incontinence. Dis Colon Rectum. 2010 Apr;53(4):414-21.

83. Kulisevsky J, Pagonabarraga J. Tolerability and safety of ropinirole versus other dopamine agonists and levodopa in the treatment of PD: meta-analysis of randomized controlled trials. Drug Saf. 2010 Feb 1;33(2):147-61.

84. Hauser RA, Panisset M, Abbruzzese G, et al on behalf of the FIRST-STEP Study Group. Double-blind trial of levodopa/ carbidopa/entacapone versus levodopa/carbidopa in early PD. Mov Disord. 2009 Mar 15;24(4):541-50.

85. Chen JJ, Swope DM, Dashtipour K. Comprehensive review of rasagiline, a second-generation monoamine oxidase inhibitor, for the treatment of PD. Clin Ther. 2007 Sep;29(9):1825-49.

86. No authors listed. Amantadine. In: McEvoy, G.K, editor. American Hospital Formulary Service- Drug Information 2005. Bethesda: American Society of Health-System Pharmacists; 2005. p. 592

87. French J, Gronseth G. Lost in a jungle of evidence: we need a compass. Neurology. 2008 Nov 11;71(20):1634-8.

88. Gronseth G, French J. Practice parameters and technology assessments: what they are, what they are not, and why you should care. Neurology. 2008 Nov 11;71(20):1639-43.

89. Zesiewicz TA, Sullivan KL, Arnulf I, et al on behalf of the Quality Standards Subcommittee of the American Academy of Neurology. Practice Parameter: treatment of nonmotor symptoms of Parkinson disease: report of the Quality Standards Subcommittee of the American Academy of Neurology. Neurology. 2010 Mar 16;74(11):924-31.

90. Horstink M, Tolosa E, Bonuccelli U, et al on behalf of the European Federation of Neurological Societies and the Movement Disorder Society-European Section. Review of the therapeutic management of Parkinson's disease. Report of a joint task force of the European Federation of Neurological Societies (EFNS) and the Movement Disorder Society-European Section (MDSES). Part II: late (complicated) Parkinson's disease. Eur J Neurol. 2006 Nov;13(11):1186-202.

91. Goetz CG, Tilley BC, Shaftman SR, et al on behalf of the Movement Disorder Society UPDRS Revision Task Force. Movement Disorder Society-sponsored revision of the Unified Parkinson's Disease Rating Scale (MDS-UPDRS): scale presentation and clinimetric testing results. Mov Disord. 2008 Nov 15;23(15):2129-70.

92. Chaudhuri KR, Martinez-Martin P, Schapira AH, et al. International multicenter pilot study of the first comprehensive self-completed nonmotor symptoms questionnaire for Parkinson's disease: the NMSQuest study. Mov Disord. 2006 Jul;21(7):916-23.

93. Chaudhuri KR, Martinez-Martin P, Brown RG, et al. The metric properties of a novel non-motor symptoms scale for Parkinson's disease: Results from an international pilot study. Mov Disord. 2007 Oct 15;22(13):1901-11.

94. Visser M, Marinus J, Stiggelbout AM, Van Hilten JJ. Assessment of autonomic dysfunction in Parkinson's disease: the SCOPA-AUT. Mov Disord. 2004 Nov;19(11):1306-12.

95. Perez Lloret S, Pirán Arce G, Rossi M, et al. Validation of a new scale for the evaluation of sialorrhea in patients with PD. Mov Disord. 2007 Jan;22(1):107-11.

96. McHorney CA, Bricker DE, Kramer AE, et al. The SWAL-QOL outcomes tool for oropharyngeal dysphagia in adults: I. Conceptual foundation and item development. Dysphagia. 2000 Summer;15(3):115-21.

97. McHorney CA, Bricker DE, Robbins J, et al. The SWAL-QOL outcomes tool for oropharyngeal dysphagia in adults: II. Item reduction and preliminary scaling. Dysphagia. 2000 Summer; 15 (3):122-33.

98. McHorney CA, Robbins J, Lomax K, et al. The SWAL-QOL and SWAL-CARE outcomes tool for oropharyngeal dysphagia in adults: III. Documentation of reliability and validity. Dysphagia. 2002 Spring:17(2):97-114.

99. Agachan F, Chen T, Pfeifer J, et al. A constipation scoring system to simplify evaluation and management of constipated patients. Dis Colon Rectum. 1996 Jun;39(6):681-5.

(selected scales for the assessment of the gastrointestinal symptoms in PD)

General scales, in which the symptoms are considered within a broad context:

- $\quad$ MDS-Unified PD Rating Scale (MDS-UPDRS) part II91

- $\quad$ Nonmotor Symptoms Questionnaire for PD (NMSQuest) ${ }^{92}$

- $\quad$ Nonmotor Symptoms Scale (NMSS) ${ }^{93}$

- $\quad$ The Scales for Outcomes in PD-Autonomic (SCOPA-AUT) ${ }^{94}$

Drooling:

- $\quad$ Sialhorrea Clinical Scale for PD (SCS-PD) ${ }^{95}$

Dysphagia:

- $\quad$ Generic Scale for Dysphagia-Related Outcomes Quality of Life (SWAL-QOL) ${ }^{96-98 a}$

Constipation:

- Cleveland Constipation Scoring System ${ }^{99 a}$

${ }^{a}$ scales that have not been specifically designed or validated for PD patients. 